\title{
Should we abandon the patient-specific instrumentation ship in total knee arthroplasty? Not quite yet!
}

\author{
László Török ${ }^{1,2}$, Péter Jávor ${ }^{1}$, Petra Hartmann', László Bánki and Endre Varga ${ }^{1 *}$
}

\begin{abstract}
Patient-specific Instrumentation (PSI) is an innovative technique aiding the precise implementation of the preoperative plan during total knee arthroplasty (TKA) by using patient-specific guides and cutting blocks. Despite of the theoretical advantages, studies have reported contradictory results, thus there is no consensus regarding the overall effectiveness of PSI. Through the critical assessment of a meta-analysis published lately, this correspondence aims to highlight the complexity of comparing the efficacy of PSI to standard instrumentation (SI). The accuracy of component alignment, patient-reported outcome measures (PROMs), surgery time, blood loss, transfusion rate, and postoperative complications are commonly used outcomes for investigating the efficacy of PSI-aided TKA. By assessing component alignment, the expertise of the surgeon(s) should be taken into consideration, since PSI may not provide benefits for expert surgeons but might improve accuracy and patient safety during the learning curve of novice surgeons. With respect to PROMs and postoperative complications, PSI may not improve short-term results; however, long-term follow up data is missing. Regarding transfusion rates, favorable trends can be observed, but further studies utilizing recent data are needed for a clear conclusion. When assessing surgery time, we suggest focusing on operating room turnover instead of procedure time.
\end{abstract}

Keywords: "arthroplasty, replacement, knee", "Surgical instruments", "Printing, three-dimensional", "Patient-specific instrumentation"

\section{Main text}

To date, there is no consensus regarding the superiority of patient-specific instrumentation (PSI) over standard instrumentation (SI) in performing total knee arthroplasty (TKA). Lately, the meta-analysis of Kizaki et al. [1] underlined lacking benefits of PSI with respect to patient-reported outcome measures (PROMs), surgery time, transfusion rate, and postoperative complications. Although the study has considerable merit, we would like to emphasize the complexity of the issue and shed light on aspects that can provide a basis for the

\footnotetext{
* Correspondence: office.trauma@med.u-szeged.hu

'Department of Traumatology, University of Szeged, Semmelweis u. 6, Szeged 6725, Hungary

Full list of author information is available at the end of the article
}

appropriate judgement of the effectiveness of the PSIaided TKA.

\section{Choosing the study period}

The study of Kizaki et al. included 38 records published between 2012 and 2018; nevertheless, the period of data collection started from 2010 in some studies. Given the dramatic technological development over the past decade, using 8-10-year-old data for the assessment of a surgical method with a software background may not reflect the effectivity of the currently available technology. The approach to software development is much different than a decade ago $[2,3]$. Accordingly, there is already a difference between the performances of 1st and 2nd generation PSI designs [4] and using data only from the past

(c) The Author(s). 2021 Open Access This article is licensed under a Creative Commons Attribution 4.0 International License, which permits use, sharing, adaptation, distribution and reproduction in any medium or format, as long as you give appropriate credit to the original author(s) and the source, provide a link to the Creative Commons licence, and indicate if changes were made. The images or other third party material in this article are included in the article's Creative Commons licence, unless indicated otherwise in a credit line to the material. If material is not included in the article's Creative Commons licence and your intended use is not permitted by statutory regulation or exceeds the permitted use, you will need to obtain permission directly from the copyright holder. To view a copy of this licence, visit http://creativecommons.org/licenses/by/4.0/ The Creative Commons Public Domain Dedication waiver (http://creativecommons.org/publicdomain/zero/1.0/) applies to the data made available in this article, unless otherwise stated in a credit line to the data. 
5 years in such a rapidly evolving field would be more reliable.

\section{Expert vs trainee surgeon}

The PSI technology strives for an improved alignment and component position with custom-fit cutting blocks and guides designed preoperatively to fit the patient's anatomy of the knee [1]. However, expert, high-volume surgeons often have been reported to achieve the same radiological accuracy for TKA with the conventional technique and with PSI $[5,6]$; The cutoff number ranges 13-50 procedure yearly for TKA to separate low-volume surgeons from high-volume surgeons [7]. The study of Kizaki et al. reported 336 patients including 29 patients with bilateral lateral femoral bowing $\left(>5^{\circ}\right)$ receiving TKAs in a 3-year-long study period from the same surgeon. The large number of cases indicates a highvolume surgeon making careful preoperative planning with long films before conventional TKAs, which could hardly be outperformed by using the PSI. Notably, one of the main advantages of the use of PSI that can increase patient safety during the learning curve of novice surgeons, as PSI might allow non-expert surgeons even with no prior experience- to achieve the same level of accuracy as expert surgeons $[5,6,8]$.

\section{Patient reported outcome measures}

Kizaki et al. utilized various PROMs (KSS knee, KSS function, KSS total, Oxford, WOMAC, KOOS symptom, KOOS pain, KOOS ADL, KOOS sports, KOOS QoL, EQ-5D VAS, SF-12 physical score, and SF-12 mental score) to assess and quantify the success rates of PSI and SI. According to their results, PSI did not improve PROMs among patients followed both for less than 1year and for 1-year or more. However, when evaluating patient satisfaction, the short follow-up time of the included studies should be taken into consideration as most records investigated a postoperative period ranging from 3 to 24 months. Some complications such as aseptic loosening can easily occur in later postoperative phases as well, affecting patient satisfaction and need for revision surgery [9]. Therefore, the long-term influence of PSI on patient satisfaction may worth further investigation.

\section{Surgery time}

Significant difference in surgery time was not found between PSI and SI groups in the meta-analysis of Kizaki et al. Although the study does not paraphrase surgery time, it corresponds to procedure time (from skin incision or torniquet placement) according to the included records. Nevertheless, the main time benefit of PSI is considered to lie in turnover time instead of procedure time, due to the reduced number of instruments and instrument trays [10]. As operating room turnover includes cleaning, and the preparation and replacement of necessary material $[11,12]$, its association with the number of trays can be presumed. In contrast to the controversy regarding PSI's procedure time advantage, improving turnover is more clearly supported by clinical data $[10,13,14]$. For this reason, the time-effectiveness of PSI should not be evaluated by taking only procedure time into consideration. Additionally, the time requirement of preoperative planning further complicates the issue.

\section{Blood loss and transfusion rate}

Despite of significantly lower blood loss by PSI, the difference between transfusion rates did not reach significance level according to Kizaki et al. The small effect size, as a potential explanation of the difference in blood loss was mentioned by the authors; however, the heterogeneity of included studies was also considerably high (71\%) regarding this parameter. Furthermore, the authors accentuated that most systematic reviews demonstrating the superiority of PSI over SI used surrogate markers such as blood loss as primary outcomes, leading to false conclusion regarding the real advantages of the PSI method. It is important to note that several studies found significantly decreased blood loss with PSI [1518], and blood loss can influence transfusion requirements. According to this, certain trends could be observed in transfusion rates in the study of Kizaki et al. as well (14\% vs $20 \%)$. In case of rapidly developing techniques such as PSI, favorable trends may be interpreted as an incentive for further development rather than as a clear lack of benefits.

\section{Complications}

The authors investigated postoperative complication rates (surgical site infection (SSI), deep vein thrombosis (DVT), and need for revision TKA) between the groups and did not find a significant difference. However, the complication rates were small (by PSI TKA: $1.3 \%$ for SSI, $1.0 \%$ for DVT, and $0.5 \%$ for revision TKA), thus it was stated by the authors as well that the pooled events were insufficient to draw a conclusion. Additionally, the short follow-up time of the included studies should be taken into consideration by revision TKA rates. Most records investigated a postoperative period ranging from 3 to 24 months. Maximum follow up was 44 months. According to the literature, aseptic loosening is one of the most common indications for revision TKA, and its $\mathrm{cu}-$ mulative incidence doubles itself from 24 to 48 months postoperatively; moreover, it displays a substantial, continuous growth in the subsequent years as well [9]. Consequently, a study period of at least 48 months would be desirable for the comprehensive investigation of 


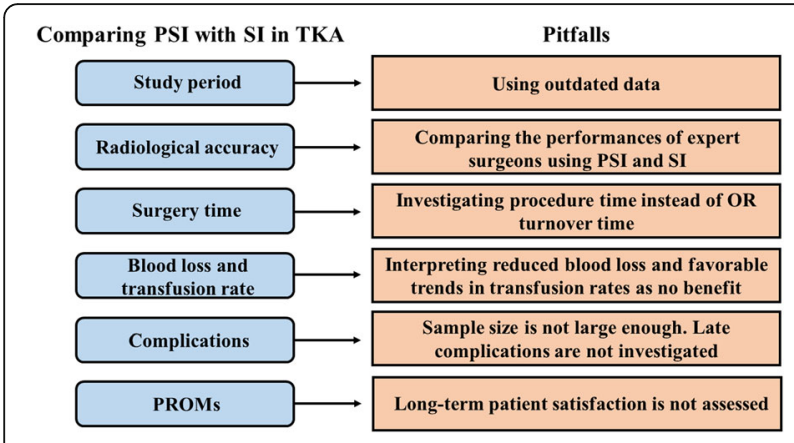

Fig. 1 Pitfalls of comparing PSI with SI in performing TKA

complications. According to this, studies in this issue commonly utilize long follow-up periods (up to 8 years) [19-21].

\section{Summary and conclusions}

In summary, PSI technology for performing TKA develop rapidly, showing promising results from some perspectives and inconsistent from others. Care must be taken to draw the right conclusions from the results of the studies, as the issue is complex and has many facets that may be interpreted differently. A summary diagram highlighting the pitfalls of comparing PSI with SI is presented in Fig. 1.

Additionally, we would like the emphasize that patient-specific techniques and 3D printing are becoming more and more accessible and affordable. Therefore, comprehensive cost-effectiveness analyses should be conducted and repeated in parallel with the development of technology. Ultimately, we suggest further discussion about the utility of PSI and emphasize the need for further research on various patient-specific systems and their long-term effects.

\section{Abbreviations}

PSI: patient specific instrumentation; SI: standard instrumentation; TKA: total knee arthroplasty; PROMs: patient-reported outcome measures; SSI: surgical site infection; DVT: deep vein thrombosis

\section{Acknowledgements}

There are no acknowledgements in association with the present study.

\section{Authors' contributions}

LT: expert in the field of orthopedics, traumatology, and sports medicine, preparation of the draft of the manuscript, contribution in study design; PJ: stylistic and grammatical revision of the manuscript, formatting the manuscript; $\mathrm{PH}$ : expert in the field of orthopedics and traumatology, provided revisions to the scientific content of the manuscript, acquisition of funding; LB: expert in the field of orthopedics and traumatology, substantial contribution in study design; EV: expert in the field of orthopedics and traumatology, coordination of the study, provided revisions to the scientific content of the manuscript.

Hereby, all authors certify that they have participated sufficiently in the work to take public responsibility for the content. All authors read and approved the final version of the manuscript.

\section{Funding}

The study was funded by the National Research, Development and Innovation Office, OTKA Research Grant: FK138839 and the Hungarian Academy of Sciences, János Bolyai Research Grant: BO/00644/21. It was further funded by the Human Resource Development Operational Programme Grant: EFOP- 3.6.3-VEKOP-16-2017-00009. Funders have not been specifically involved in and did not have an influence on the scientific content of our present study.

\section{Availability of data and materials}

Our present study uses published data only.

\section{Declarations}

Ethics approval and consent to participate Not applicable.

\section{Consent for publication}

Not applicable.

\section{Competing interests}

The authors declare that they have no competing interests.

\section{Author details}

'Department of Traumatology, University of Szeged, Semmelweis u. 6, Szeged 6725, Hungary. ${ }^{2}$ Department of Sports Medicine, University of Szeged, Tisza Lajos Krt. 107, Szeged 6725, Hungary.

Received: 27 April 2021 Accepted: 4 August 2021

Published online: 24 August 2021

\section{References}

1. Kizaki K, Shanmugaraj A, Yamashita F, Simunovic N, Duong A, Khanna V, et al. Total knee arthroplasty using patient-specific instrumentation for osteoarthritis of the knee: a meta-analysis. BMC Musculoskelet Disord. 2019; 20(1):561. https://doi.org/10.1186/s12891-019-2940-2.

2. Silva LB, Jimenez RC, Blomberg N, Luis Oliveira J. General quidelines for biomedical software development. F1000Res. 2017;6:273. https://doi.org/1 0.12688/f1000research.10750.2.

3. Steinberg EL, Segev E, Drexler M, Ben-Tov T, Nimrod S. Preoperative planning of orthopedic procedures using digitalized software systems. Isr Med Assoc J. 2016;18(6):354-8.

4. Kwon OR, Kang KT, Son J, Suh DS, Heo DB, Koh YG. Patient-specific instrumentation development in TKA: 1st and 2nd generation designs in comparison with conventional instrumentation. Arch Orthop Trauma Surg. 2017;137(1):111-8. https://doi.org/10.1007/s00402-016-2618-2.

5. Sanz-Ruiz P, Matas-Diez JA, Carbo-Laso E, Perez-Mañanes R, Vaquero-Martín $J$. Patient-specific instrument can improve functional and radiographic results during learning curve for Oxford Unicompartmental knee arthroplasty. J Knee Surg. 2019;32(2):180-5. https://doi.org/10.1055/s-0038-1 636837

6. Jones GG, Logishetty K, Clarke S, Collins R, Jaere M, Harris S, et al. Do patient-specific instruments (PSI) for UKA allow non-expert surgeons to achieve the same saw cut accuracy as expert surgeons? Arch Orthop Trauma Surg. 2018;138(11):1601-8. https://doi.org/10.1007/s00402-018-30319.

7. Kazarian GS, Lawrie CM, Barrack TN, Donaldson MJ, Miller GM, Haddad FS, et al. The impact of surgeon volume and training status on implant alignment in Total knee arthroplasty. J Bone Joint Surg Am. 2019;101(19): 1713-23. https://doi.org/10.2106/JBJS.18.01205.

8. $\mathrm{Ng} \mathrm{CTJ,} \mathrm{Newman} \mathrm{S,} \mathrm{Harris} \mathrm{S,} \mathrm{Clarke} \mathrm{S,} \mathrm{Cobb} \mathrm{J.} \mathrm{Patient-specific}$ instrumentation improves alignment of lateral unicompartmental knee replacements by novice surgeons. Int Orthop. 2017;41(7):1379-85. https:// doi.org/10.1007/s00264-017-3468-4

9. Khan M, Osman K, Green G, Haddad FS. The epidemiology of failure in total knee arthroplasty: avoiding your next revision. Bone Joint J. 2016;98-B(1 Suppl A):105-12.

10. Attard A, Tawy GF, Simons M, Riches P, Rowe P, Biant LC. Health costs and efficiencies of patient-specific and single-use instrumentation in total knee arthroplasty: a randomised controlled trial. BMJ Open Qual. 2019;8(2): e000493. https://doi.org/10.1136/bmjoq-2018-000493. 
11. Costa ADS Jr. Assessment of operative times of multiple surgical specialties in a public university hospital. Einstein (Sao Paulo). 2017:15:200-5.

12. Wu A, Brovman EY, Whang EE, Ehrenfeld JM, Urman RD. The Impact of Overestimations of Surgical Control Times Across Multiple Specialties on Medical Systems. J Med Syst. 2016;40(4):95. https://doi.org/10.1007/s10916016-0457-X.

13. Renson L, Poilvache $P$, Van den Wyngaert $H$. Improved alignment and operating room efficiency with patient-specific instrumentation for TKA. Knee. 2014;21(6):1216-20. https://doi.org/10.1016/j.knee.2014.09.008.

14. Tibesku CO, Hofer P, Portegies W, Ruys CJ, Fennema P. Benefits of using customized instrumentation in total knee arthroplasty: results from an activity-based costing model. Arch Orthop Trauma Surg. 2013;133(3):405-11. https://doi.org/10.1007/s00402-012-1667-4

15. Gong S, Xu W, Wang R, Wang Z, Wang B, Han L, et al. Patient-specific instrumentation improved axial alignment of the femoral component, operative time and perioperative blood loss after total knee arthroplasty. Knee Surg Sports Traumatol Arthrosc. 2019;27(4):1083-95. https://doi.org/1 0.1007/s00167-018-5256-0

16. Schotanus MG, Thijs E, Heijmans M, Vos R, Kort NP. Favourable alignment outcomes with MRI-based patient-specific instruments in total knee arthroplasty. Knee Surg Sports Traumatol Arthrosc. 2018;26(9):2659-68. https://doi.org/10.1007/s00167-017-4637-0

17. Alcelik I, Blomfield M, Öztürk C, Soni A, Charity R, Acornley A. A comparison of short term radiological alignment outcomes of the patient specific and standard instrumentation for primary total knee arthroplasty: a systematic review and meta-analysis. Acta Orthop Traumatol Turc. 2017;51(3):215-22. https://doi.org/10.1016/j.aott.2017.02.001.

18. Mannan A, Smith TO. Favourable rotational alignment outcomes in PSI knee arthroplasty: a level 1 systematic review and meta-analysis. Knee. 2016;23(2): 186-90. https://doi.org/10.1016/j.knee.2015.08.006.

19. Hsu RW, Hsu WH, Shen WJ, Hsu WB, Chang SH. Comparison of computerassisted navigation and conventional instrumentation for bilateral total knee arthroplasty: The outcomes at mid-term follow-up. Medicine (Baltimore). 2019;98(47):e18083. https://doi.org/10.1097/MD.0000000000018083.

20. Postler A, Lützner C, Beyer F, Tille E, Lützner J. Analysis of Total knee arthroplasty revision causes. BMC Musculoskelet Disord. 2018;19(1):55. https://doi.org/10.1186/s12891-018-1977-y.

21. Lee DH, Lee SH, Song EK, Seon JK, Lim HA, Yang HY. Causes and clinical outcomes of revision Total knee arthroplasty. Knee Surg Relat Res. 2017; 29(2):104-9. https://doi.org/10.5792/ksrr.16.035.

\section{Publisher's Note}

Springer Nature remains neutral with regard to jurisdictional claims in published maps and institutional affiliations.

Ready to submit your research? Choose BMC and benefit from:

- fast, convenient online submission

- thorough peer review by experienced researchers in your field

- rapid publication on acceptance

- support for research data, including large and complex data types

- gold Open Access which fosters wider collaboration and increased citations

- maximum visibility for your research: over $100 \mathrm{M}$ website views per year

At $\mathrm{BMC}$, research is always in progress.

Learn more biomedcentral.com/submissions 